\title{
Isolation and Partial Characterization of an Extracellular Branched D-Glucan from Monilinia fructigena
}

\author{
By S. A. ARCHER \\ Department of Botany, University of Bristol, Bristol BS8 IUG \\ J. R. CLAMP AND DANIELLE MIGLIORE* \\ Department of Medicine, University of Bristol, Bristol BS8 ITD
}

(Received 4 March 1977)

\begin{abstract}
Rapidly growing liquid shake cultures of Monilinia fructigena secreted a polysaccharide which caused an increase in the viscosity of the nutrient liquor. Glucose/malt medium supported most rapid growth and greatest polysaccharide accumulation. Acetone precipitation and dialysis resulted in preparations which were essentially ash and nitrogen free. Gel chromatography indicated that the polysaccharide was polydisperse over the mol. wt range 80000 to 5000 . Molecular size was positively correlated with viscosity and inversely correlated with aqueous solubility. Carbohydrate analyses by paper and gas-liquid chromatography indicated that glucose accounted for $>90 \%$ of the sugar residues present. Mannose and galactose were also detected. Charged groups were absent. Periodate oxidation revealed that the main linkage was $\mathrm{I} \rightarrow 4$, with a low proportion of $\mathrm{I} \rightarrow 2$ linkages. The degree of branching varied between every fifth and every tenth residue. Linkages of $\mathrm{I} \rightarrow 3$ type were virtually absent. Interaction with concanavalin $A$ indicated the presence of non-reducing terminal $\alpha$-D-glucopyranosyl or $\alpha$-D-mannopyranosyl residues.
\end{abstract}

\section{INTRODUCTION}

Extracellular polysaccharides are synthesized by a variety of fungi and occur either as a discrete capsule or sheath (Szaniszlo, Wirsen \& Mitchell, I968; Reiss, I97I), or as a diffuse slime dispersed in the culture medium (Buck et al., 1968). The extent to which dispersion occurs is probably largely determined by the degree of agitation during culture. In terms of chemical composition, glucans, sometimes containing trace amounts of other sugars (Gorin \& Spencer, 1968), are predominant, although heteropolymers have also been described (Goatley, 1968; Gorin \& Spencer, 1968; Gorin \& Everleigh, 1970).

Extracellular polysaccharide production by a member of the Sclerotiniaceae was first described by Thomas ( I930) who noted a gelatinous slime on the hyphal surface of Sclerotinia sclerotiorum which could be washed off and precipitated by alcohol. A possibly identical polysaccharide named sclerotan (see Marshall, 1974) was isolated from sclerotia of Sclerotinia libertiana $(=S$. sclerotiorum) by Japanese workers. More recently, Willetts (I97I, I972) mentioned the copious production of extracellular mucilage by both $S$. sclerotiorum and Monilinia ( = Sclerotinia) fructicola but no characterization was attempted. A polysaccharide secreted by the latter species was also the subject of a brief report by Feather \& Malek (1972). Their results indicated that the material was a highly branched glucan in which $\mathrm{I} \rightarrow 3$ linkages predominated.

In view of the probable importance of extracellular polysaccharides in the overall biology of the Sclerotiniaceae (Willetts, 197I, 1972) and the possible commercial use of such

* Present address: Laboratoire des Protéines, 45 Rue des St Pères, 75006 Paris, France. 
products as food additives (Gorin \& Spencer, 1968), anti-tumour agents (Whistler, Bushway \& Singh, 1976) and flocculants (Zajic \& LeDuy, 1973), it was decided to investigate polysaccharide secretion by the European brown rot species Monilinia fructigena (Aderh. \& Ruhl.) Honey (= Sclerotinia fructigena Aderh. \& Ruhl.).

\section{METHODS}

Organism and growth conditions. A monoconidial isolate of Monilinia fructigena (ATCC26106), maintained on potato/carrot agar, was used for all studies of polysaccharide secretion. For routine production of polysaccharide, glucose/malt medium was used which contained (per litre deionized water): $35 \mathrm{~g}$ malt extract (Boots Pure Drug Co., Nottingham) and $\mathrm{I}$ g glucose. The medium was boiled for 10 min to precipitate a protein-tannin complex (de Clerck, 1957), filtered, and $75 \mathrm{ml}$ was dispensed into $250 \mathrm{ml}$ conical flasks and sterilized by autoclaving ( $12 \mathrm{I}^{\circ} \mathrm{C}$ for $20 \mathrm{~min}$ ). Flasks were each inoculated with $10^{6}$ conidia (Archer, 1973) and incubated at $25^{\circ} \mathrm{C}$. Cultures were incubated static for $16 \mathrm{~h}$ and then transferred to a reciprocating shaker ( 100 strokes $\mathrm{min}^{-1}$, stroke $4 \mathrm{~cm}$ ) which induces pellet form of growth (Archer, 1973).

\section{Analytical procedures}

Viscometry. Before viscometry and all other physico-chemical measurements, solutions were filtered through a Sartorius membrane filter (pore size $0.45 \mu \mathrm{m}$ ). Viscosity was measured using an Ostwald type capillary viscometer at $30{ }^{\circ} \mathrm{C}$. Results are presented relative to the viscosity of water, $\eta_{\text {rel }}$, or as intrinsic viscosity, $[\eta]$.

Specific refractive increment was measured using a Zeiss dipping refractometer.

Partial specific volume was calculated from density measurements made using standard pycnometric procedures.

Number average molecular weight $\left(\bar{M}_{\mathrm{r}}\right)$. Osmotic pressure $(\pi)$ at a range of concentrations $(c)$ was measured using a Hewlett Packard 50I membrane osmometer. $\pi / c$ was plotted against $c$; extrapolation to infinite dilution enables $\bar{M}_{\mathrm{n}}$ to be calculated from the equation:

$$
\bar{M}_{\mathrm{n}}=\frac{R T}{(\pi / c)_{c \rightarrow 0}}
$$

Ultracentrifugation. Solutions $(0.5 \%, \mathrm{w} / \mathrm{v})$ in water were subjected to sedimentation velocity analysis in a Beckman Model E ultracentrifuge using schlieren optics.

Infrared spectroscopy. Spectra of samples dispersed in $\mathrm{KBr}$ discs were obtained using a Perkin Elmer 257 grating spectrophotometer.

Gel filtration. Samples (up to $5 \mathrm{mg}$ dissolved in $\mathrm{I} \cdot 0$ to $5.0 \mathrm{ml}$ elution solvent) were applied to columns $(35.0 \times 3.0 \mathrm{~cm})$ of Sephadex G-100 or G-25 previously equilibrated with 0.2 M-potassium phosphate buffer, pH 7.0. Elution rate (descending flow) was $\mathrm{IO}_{\mathrm{ml} \mathrm{h}}^{-1}$ and fractions of approx. $4 \mathrm{ml}$ were collected. Columns were calibrated with Blue Dextran 2000 (Pharmacia), a range of dextrans (Sigma) of $\bar{M}_{w} 20000$ to 80000 , and sucrose. The relatively large sample volumes applied were necessary because of the low solubility and high viscosity of some polysaccharide fractions. This inevitably resulted in some zone broadening. Carbohydrates in fractions were estimated quantitatively by the phenol-sulphuric acid method of Dubois et al. (1956) using glucose as standard.

Zone electrophoresis was performed on Whatman glass fibre paper GF 8I which had been pretreated by heating to $500^{\circ} \mathrm{C}$ for $\mathrm{I} \mathrm{h}$ to remove traces of cellulose. Buffers used were: $0.05 \mathrm{M}$-sodium phthalate $\mathrm{pH} 3.3$; $0.05 \mathrm{M}$-potassium phosphate $\mathrm{pH} 7.0$ containing $0.01 \mathrm{M}$-EDTA; and boric acid/o.05 $\mathrm{M}-\mathrm{NaOH} \mathrm{pH}$ 10.0. The paper was soaked in buffer and 50 to $100 \mu \mathrm{g}$ of polysaccharide was applied to a spot approx. I $\mathrm{cm}$ in diameter at the origin. The electrophoresis was performed in a Shandon Southern low voltage apparatus at $20{ }^{\circ} \mathrm{C}$; the same buffer was used in both buffer and electrode compartments. The voltage applied was either I00 V for $16 \mathrm{~h}\left(0.9 \mathrm{~mA} \mathrm{~cm}^{-1}\right)$ or $300 \mathrm{~V}$ for $\left.8 \mathrm{~h}(3 \mathrm{~mA} \mathrm{~cm})^{-1}\right)$. Higher voltages were not possible due to moisture loss from the paper. Starch and dextrans were used as neutral standards; pectin (degree of esterification, $75 \%$ and totally de-esterified pectic acid were used as markers carrying weak and strong negative charges respectively. Carbohydrates were visualized by dipping in sulphonated $\alpha$-naphthol reagent (Devor, 1950) prepared in $95 \%(\mathrm{v} / \mathrm{v})$ ethanol.

Elemental analyses were performed by Mr M. West of the Microanalytical Laboratory, School of Chemistry, University of Bristol.

Protein content was measured by the method of Lowry et al. (1951) using bovine serum albumin as standard. Acid hydrolysis. Polysaccharide samples were hydrolysed in $3 \mathrm{M}-\mathrm{HCl}$ at $110^{\circ} \mathrm{C}$ under nitrogen for intervals up to $\mathrm{I} 2 \mathrm{~h}$. Prior to chromatography hydrolysates were neutralized with Dowex I-X8 $\left(\mathrm{OH}^{-}\right.$form). 
Chromatography of sugars. For descending paper (Whatman no. 1) chromatograms the following solvent systems were used: ethyl acetate/pyridine/acetic acid/water (5:5:1:3, by vol.); butan-I-ol/acetic acid/water (4:1:5, by vol., upper phase) and propan-I-ol/water/ethyl acetate (7:2:1, by vol.). For thin-layer chromatograms, Whatman cellulose powder $\mathrm{CC}_{4} \mathrm{I}$ was used as support and butan-I-ol/acetic acid/water (3:I:I, by vol.) as solvent (Shah \& Loewus, 1967). All chromatograms were run in solvent-equilibrated tanks at $22{ }^{\circ} \mathrm{C}$. Sugars on chromatograms were visualized by spraying with silver nitrate in acetone followed by ethanolic sodium hydroxide (Trevelyan, Procter \& Harrison, 1950).

Gas-liquid chromatography. Polysaccharides were also analysed by a modification of the gas chromatographic method of Clamp (1974). The material to be analysed (0.05 mg) together with mannitol (0.1 $\mu$ mol) as internal standard was thoroughly dried in a $2 \mathrm{ml}$ ampoule. To this was added $\mathrm{I} \mathrm{M}-\mathrm{HCl}$ in dry methanol $(0.5 \mathrm{ml})$ and after gassing for a few minutes with nitrogen, the ampoule was sealed and heated at $85^{\circ} \mathrm{C}$ for $24 \mathrm{~h}$. The solution was then neutralized with silver carbonate, acetic anhydride $(0.05 \mathrm{ml})$ was added, and the solution kept at room temperature for $6 \mathrm{~h}$. The ampoule was centrifuged and the supernatant was transferred to a $5 \mathrm{ml}$ pear-shaped flask. The residue was triturated with two further additions of methanol $(0.5 \mathrm{ml})$ and after centrifugation the supernatants were combined. A second internal standard, arabinitol $(0 \cdot 1 \mu \mathrm{mcl})$ in methanol, was added and the solution was flash evaporated at $35^{\circ} \mathrm{C}$. The flask was kept in a vacuum desiccator over $\mathrm{P}_{2} \mathrm{O}_{5}$ until required for analysis. The remaining steps were as outlined in Clamp (1974).

Periodate oxidation. The polysaccharide $(0.1 \mathrm{mg})$ was reacted with $15 \mathrm{~mm}$-sodium metaperiodate solution ( $\mathrm{ml}$ ) at room temperature in the dark, the procedure being carried out in duplicate. At intervals a sample $(25 \mu$ l) was taken, diluted to $5 \mathrm{ml}$ with distilled water and the absorbance read at $223 \mathrm{~nm}$ (Hughes \& Clamp, 1972). The amount of unreacted periodate was estimated from a calibration curve in which absorbance at $223 \mathrm{~nm}$ was plotted against molarity of periodate. The standard solution used for the calibration curve was made up of sodium periodate and sodium iodate in complementary concentrations to a total concentration of $15 \mathrm{~mm}$.

Estimation of surviving monosaccharides and oxidation products. When periodate reduction was complete, sodium borohydride $(4 \mathrm{mg})$ was added to the solution which was left for $24 \mathrm{~h}$. Glacial acetic acid (12.5 $\mu \mathrm{l})$ was added and the solution dialysed against distilled water for $24 \mathrm{~h}$ at $4^{\circ} \mathrm{C}$. Mannitol $(0.05 \mu \mathrm{mol})$ was added as the first internal standard, and the solution was freeze-dried to a small volume and transferred to a $2 \mathrm{ml}$ ampoule. The ampoule was dried and kept in a vacuum desiccator over $\mathrm{P}_{2} \mathrm{O}_{5}$ for at least $48 \mathrm{~h}$. Two further internal standards, digol ( $(0 . \mathrm{I} \mu \mathrm{mol})$ and trigol ( $0 . \mathrm{I} \mu \mathrm{mol})$ in methanol $(0.05 \mathrm{ml})$ were added to the ampoule, followed by methanolic $\mathrm{HCl}(0.5 \mathrm{ml})$. The remainder of the procedure was identical to that outlined above except that the gas chromatograph was temperature-programmed from $100{ }^{\circ} \mathrm{C}$ to $200{ }^{\circ} \mathrm{C}$ at $\mathrm{I}^{\circ} \mathrm{C} \mathrm{min}^{-1}$. Digol and trigol were obtained from BDH.

The liberation of formic acid during periodate oxidation was determined using the duplicate sample. When periodate reduction was complete, ethanediol $(0 . \mathrm{I} \mathrm{ml})$ was added and the solution left for $\mathrm{I} h$ at room temperature. The formic acid so produced was titrated against o. OI M-NaOH to a methyl red end-point.

Reaction with lectins. Interaction with concanavalin A (Miles Laboratories, Stoke Poges, Buckinghamshire) was investigated on Ouchterlony diffusion plates. The agar medium was prepared as follows. Ionagar ( $\mathrm{\%}$, w/v; Oxoid) together with $\mathrm{NaCl}(0.9 \%, \mathrm{w} / \mathrm{v})$ and $0 \cdot \mathrm{I} \mathrm{M}$-potassium phosphate buffer $\mathrm{pH} 7 \cdot 0$ were dissolved by heating to $100^{\circ} \mathrm{C}$ for $20 \mathrm{~min}$. Sodium azide $(0 \cdot \mathrm{I} \%, \mathrm{w} / \mathrm{v})$ was added and the agar poured on to glass slides to give sheets of 2 to $3 \mathrm{~mm}$ depth. A central well $(8 \mathrm{~mm}$ diam.) was cut surrounded by six peripheral wells ( $5 \mathrm{~mm}$ diam.). Concanavalin A (3 to $6 \mathrm{mg} \mathrm{ml}^{-1}$ in $0.1 \mathrm{M}$-potassium phosphate $\mathrm{pH} 7 \cdot 0$ containing I $\mathrm{M}-\mathrm{NaCl}$ ) was introduced to the central well and polysaccharide preparations into the peripheral wells. Plates were incubated in moist chambers at $25^{\circ} \mathrm{C}$ and observations were made at intervals up to $72 \mathrm{~h}$. Other lectins were as used by Tanner \& Anstee (1976).

Stains. Periodic acid-Schiff staining (PAS) was performed as described by Pearse (1968). Fluorescein isothiocyanate (FITC)-conjugated concanavalin A was obtained from Miles Laboratories. Films of polysaccharide were dried on to glass slides and irrigated with FITC-concanavalin A ( $\left.2 \mathrm{mg} \mathrm{ml}^{-1}\right)$ in halfsaturated $\mathrm{NaCl}$ containing $\mathrm{O} \cdot \mathrm{I}$ M-sodium acetate buffer, $\mathrm{pH} 5.4$. After staining (30 to $60 \mathrm{~min}$ ), preparations were washed thoroughly with $\mathrm{I} \mathrm{M}-\mathrm{NaCl}$.

Alcian Blue 8GX and Alcian Green $2 \mathrm{GX}$, obtained from G. T. Gurr (Searle Scientific Services, High Wycombe, Buckinghamshire), were used as $\mathrm{I} \%(\mathrm{w} / \mathrm{v})$ solutions in $3 \%(\mathrm{v} / \mathrm{v})$ acetic acid. 


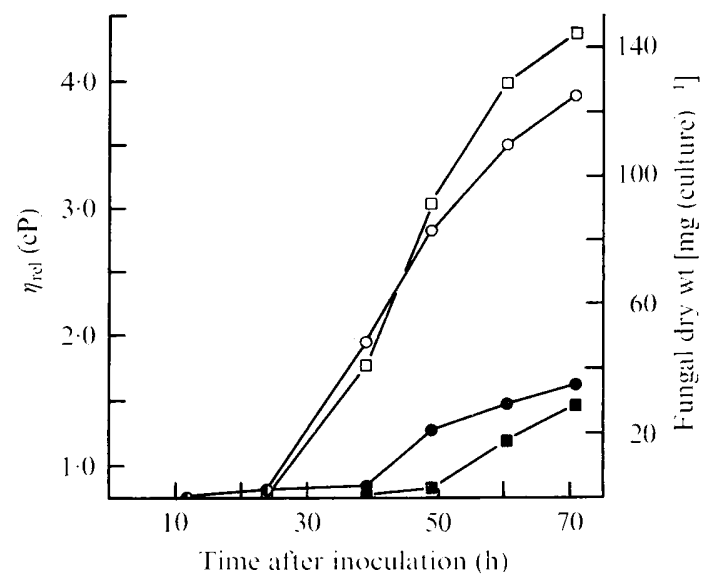

Fig. I. Growth of Monilinia fructigena and changes in viscosity of glucose/malt medium. Growth estimated as dry weight in shaken $(\bigcirc)$ and still cultures $(\bullet)$. Relative viscosity in centipoise ( $\mathrm{cP}=\mathrm{I} \mathrm{mPa} \mathrm{s}$ ) of the filtrate from the same shaken ( $\square$ ) and still ( $\square$ ) cultures. Results are the mean of three replicates.

\section{RESULTS}

Growth and polysaccharide secretion

Cultures which were shaken grew more rapidly and produced polysaccharide earlier and in greater amounts than stationary ones (Fig. I). Similar polysaccharide production was obtained when galactose or mannose were substituted for glucose. Of the growth media tried [including all of those used by Archer (1973)], hexose/malt was the most suitable for polysaccharide secretion. Usually the growth rate was related to medium viscosity, the only exception being Czapek-Dox medium which supported slow growth and yet resulted in considerable polysaccharide accumulation. This anomaly may be connected with the provision of nitrate in this medium, a form of nitrogen assimilated only slowly by $M$. fructigena (S. A. Archer, unpublished observations). Illumination had no effect on polysaccharide secretion.

\section{Isolation and purification}

Cultures grown on glucose/malt medium were harvested after $48 \mathrm{~h}$, the mycelium was removed by centrifugation $(2000 \mathrm{~g}, 10 \mathrm{~min})$ and an equal volume of acetone was added to the decanted supernatant. The gelatinous precipitate was removed, washed with $50 \%(\mathrm{v} / \mathrm{v})$ aqueous acetone and redissolved in a minimum quantity of warm $\left(50{ }^{\circ} \mathrm{C}\right)$ water. Two further precipitations gave a near-white amorphous solid, fraction I (FrI), which could be crushed to a powder when thoroughly dried.

After each successive precipitation FrI became more difficult to redissolve in water. It seems probable that acetone was selectively precipitating the least soluble components of a heterogeneous mixture although little polysaccharide could be recovered from the supernatants. Alternatively, dehydration may involve some conformational change which is not completely reversed on rehydration. The final preparation of FrI would not dissolve completely in neutral aqueous solvents even at $100{ }^{\circ} \mathrm{C}$; it was no more soluble in I $\mathrm{M}-\mathrm{NaOH}$, dimethylformamide or dimethyl sulphoxide. Solutions were always viscous and slightly turbid. For this reason, samples subjected to only two precipitations were used for electrophoresis and gel chromatography.

The supernatant from the first precipitation was made to $90 \%(\mathrm{v} / \mathrm{v})$ ethanol and allowed to stand for $\mathrm{I} 6 \mathrm{~h}$ at $2{ }^{\circ} \mathrm{C}$. After carefully decanting the supernatant, the fine precipitate was dissolved in and dialysed $\left(40 \mathrm{~h}, 2{ }^{\circ} \mathrm{C}\right)$ against distilled water and finally lyophilized at I3.3 Pa. The light brown water-soluble powder was designated fraction II (FrII). Both fractions were stored dry at room temperature. Under these conditions they were stable for 
Table I. Physico-chemical properties of the polysaccharide fractions from Monilinia fructigena

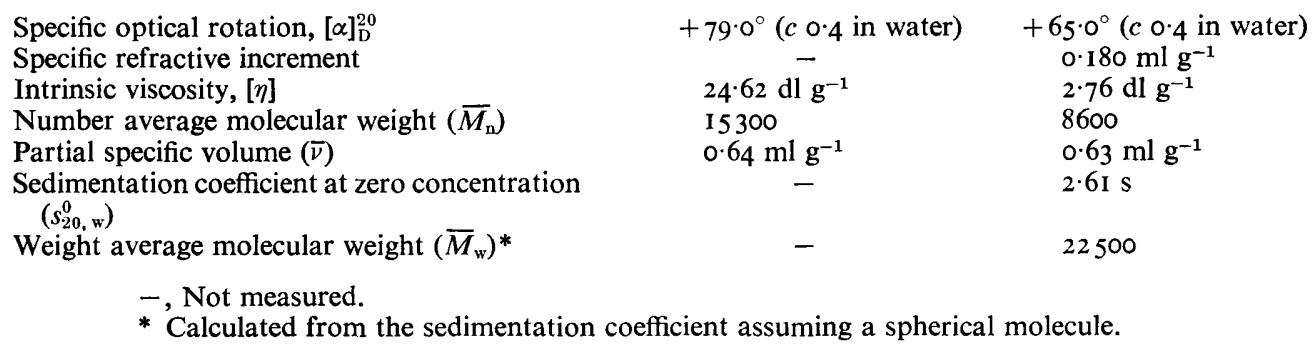

at least 2 years. Typical yields were $75 \mathrm{mg}$ of FrI and I I $\mathrm{mg}$ of FrII from $300 \mathrm{mg}$ mycelium in $100 \mathrm{ml}$ medium over $50 \mathrm{~h}$ incubation.

\section{Physico-chemical properties}

Table I summarizes the physico-chemical parameters determined for the two polysaccharide fractions. Turbidity and poor solubility prevented some measurements on FrI.

Plots of $\eta_{\mathrm{sp}} / c$ against $c$ deviated from linearity. At extreme dilution, viscosity was higher than expected for an ideal solution. The values for apparent intrinsic viscosity were obtained by extrapolating from the linear portion of the concentration range. The anomalously high viscosity at extreme dilution may have been caused by interaction between the polysaccharide and the glass walls of the capillary.

Velocity sedimentation of FrII revealed a single broad peak indicative of sample polydispersity. The area below the peak was smaller than expected on the basis of sample concentration and refractive increment, suggesting that a considerable amount of material was not being detected by the schlieren optical system.

\section{Gel filtration}

Chromatography on Sephadex G-IOo revealed that both FrI and FrII were polydisperse mixtures of saccharides with a wide range of molecular sizes. Higher molecular weight components predominated in FrI while FrlI consisted almost entirely of low molecular weight fragments (Fig. 2). Fraction I eluted over a $\bar{M}_{\mathrm{w}}$ range of approximately 80000 to I0000. $K_{\mathrm{av}}$ at the peak was 0.23 , corresponding to a dextran of $\bar{M}_{\mathrm{w}}=25500$. The high molecular weight material in FrII gave rise to a small peak, but the bulk of this fraction was of very much lower molecular weight. A considerable proportion (approx. $20 \%$ ) of FrII eluted at a point coincident with or after the elution volume of sucrose.

\section{Zone electrophoresis}

On electrophoresis, fractions I and II behaved as if carrying a small net negative charge and no charge, respectively. This was further examined using sub-fractions obtained from gel filtration (Fig. 2). The behaviour of these four fractions on electrophoresis is shown in Fig. 3. In all buffer systems neutral molecules migrated slowly towards the cathode due to electro-osmosis. Fraction IIa and FrIIb consisted mainly of components carrying little or no charge at $\mathrm{pH} 7 \cdot 0$, whereas FrIa and FrIb behaved as if carrying a small net negative charge of similar magnitude to that of pectin. In the other buffer systems, the behaviour was similar although there was some suppression of negative charge at $\mathrm{pH} 3.3$ as shown by the reduced mobility of pectic acid. At this $\mathrm{pH}$ there is some indication of charge suppression on FrIb, but the other preparations exhibited essentially similar behaviour at all three $\mathrm{pH}$ 


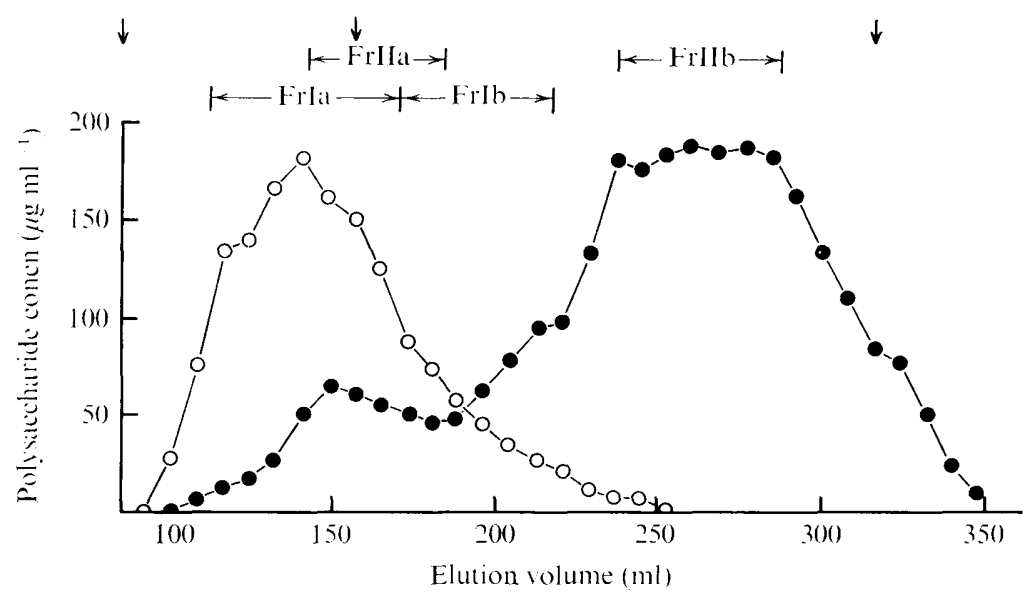

Fig. 2. Gel chromatograply of Monilinia fructigena polysaccharide fractions $I(\bigcirc)$ and II (O) on Sephadex G-I00. Vertical arrows indicate, from left to right; $V_{0}$ of the column, $V_{\mathrm{e}}$ of Dextran $\left(\bar{M}_{\mathrm{w}} 20000\right)$ and $V_{\mathrm{e}}$ of sucrose. Vertical bars denote the range of eluate included in the subfractions $\mathrm{Ia}$ and Ib, and IIa and IIb.

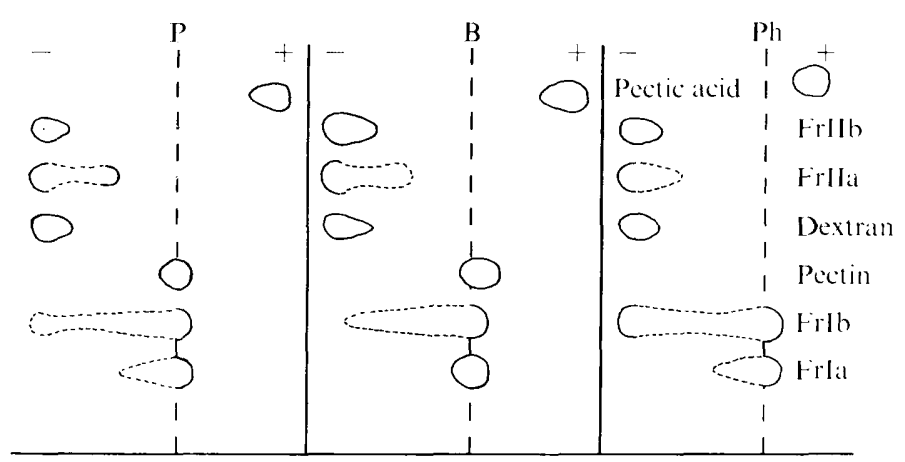

Fig. 3. Electrophoresis of Monilinia fructigena polysaccharide fractions Ia and Ib and IIa and IIb in phosphate $(P)$, borate $(B)$ and phthalate $(P h)$ buffers. The dashed line indicates the origin.

values. Fraction Ib and Frlla both showed considerable tailing, an indication of polydispersity. There was no evidence for complexing between the polysaccharide and borate, a result in agreement with other observations on fungal glucans (Fleet \& Manners, 1975). An alternative explanation for the pattern obtained is that FrI was effectively rendered immobile (with respect to the paper) by its high viscosity. This would agree with the observation that the ability to behave as a neutral molecule was inversely proportional to molecular size and viscosity within the series FrIa, FrIb, FrIIa, FrIIb. Further support for this hypothesis comes from the observation that when papers were irrigated under gravity, as in chromatography, the rate of migration of FrI was considerably less than that of Blue Dextran 2000 which has a very high molecular weight and fairly low viscosity.

\section{Chemical analysis}

Elemental analysis of FrI and FrII gave the results in Table 2. The proportions of C, H and $\mathrm{O}$ are close to the theoretical values for a glucan. The large proportion of oxygen in both fractions precludes the presence of lipid, a conclusion supported by gas-liquid chromatography and by the absence of any chloroform-soluble material either in the native polysaccharide or following acid hydrolysis. 
Table 2. Elemental analysis of polysaccharide fractions from Monilinia fructigena

Results are expressed as percentages by weight.

$\begin{array}{lcc}\text { Element } & \text { Fraction I } & \text { Fraction II } \\ \mathrm{N} & 0 . \mathrm{I} 4 & 0.06 \\ \mathrm{C} & 44.29 & 42 \cdot 80 \\ \mathrm{H} & 5.80 & 6 \cdot 10 \\ \text { O (by difference) } & 49.16 & 50.50 \\ \mathrm{P} & 0 & 0 \\ \text { S } & 0 & 0 \\ \text { Mineral residue } & 0.6 \mathrm{r} & 0.54\end{array}$

Table 3. Periodate oxidation of polysaccharide fractions from Monilinia fructigena

Results are expressed relative to $100 \mathrm{~mol}$ of glucose in the original sample.

$\begin{array}{ccc}\text { Before oxidation } & \text { Fraction I } & \text { Fraction II } \\ \text { Glucose } & 100 & \text { I00 } \\ \text { After oxidation } & & \\ \text { Glucose } & \text { I9 } & \text { I I } \\ \text { Erythritol } & 54 & 69 \\ \text { Threitol } & 0 & 0 \\ \text { Glycerol } & 27 & 23 \\ \text { Formic acid } & 2 \text { I } & \text { I2 }\end{array}$

The traces of nitrogen in FrI and to a lesser extent FrII suggest the presence of a small amount of contaminating protein. This was confirmed by the detection of traces of certain enzymes in both fractions although no protein could be detected using the Folin-Ciocalteau reagent.

\section{Sugar composition}

Acid hydrolysis of both fractions followed by paper and thin-layer chromatography revealed glucose as the predominant monosaccharide. When hydrolysed for a short time, a spot of $R_{\mathrm{Glc}} 0.53$ was present on thin-layer chromatograms. This component became progressively less abundant as the hydrolysis time was increased and may have been an oligosaccharide of glucose. Heavily loaded chromatograms indicated the presence of small amounts of hexoses other than glucose but resolution under these conditions was not sufficient for precise identification.

Analysis by gas-liquid chromatography confirmed that the major monosaccharide present was glucose. In both fractions this monosaccharide accounted for approx. $92 \%$ of the total carbohydrate with, in addition, $4 \%$ mannose, $3 \%$ galactose and trace amounts of other sugars.

\section{Periodate oxidation}

The results of periodate oxidation of FrI and FrII showed that the bulk of the glucose residues were oxidized by periodate (Table 3). In FrI only one glucose residue in five survived oxidation. That these represent branch points was confirmed by the production of an almost identical number of formic acid molecules. Formic acid can only arise from glucose that is unsubstituted at $\mathrm{C}-2, \mathrm{C}-3$ and $\mathrm{C}-4$ as would be the case for non-reducing end-groups terminating a chain. The predominant linkage is $\mathrm{I} \rightarrow 4$ which accounts for the fact that most of the glucose is susceptible to periodate and during oxidation is cleaved between $\mathrm{C}-2$ and $\mathrm{C}-3$ giving, on reduction, erythritol. A small amount (approx. $6 \%$ ) of $\mathrm{I} \rightarrow 2$ linkages are present as shown by the yield of glycerol which is correspondingly greater than that of formic acid. Oxidation of $\mathrm{I} \rightarrow 6$ linked residues or non-reducing endgroups would by contrast result in equal yields of glycerol and formic acid. 
Fraction II is less highly branched than FrI, only one in ten glucose residues carrying a branch chain. Nevertheless the predominant linkage is once again $\mathrm{I} \rightarrow 4$ with a slightly higher proportion of $\mathrm{I} \rightarrow 2$ linkages than in FrI.

The infrared spectra of both polysaccharide fractions were devoid of well defined absorption maxima in the region 800 to $960 \mathrm{~cm}^{-1}$. Some samples of FrI showed a weak absorption maximum at $890 \mathrm{~cm}^{-1}$ indicative of $\beta$-glucosidic linkages (Barker et al., 1954).

\section{Reaction with concanavalin A}

Initial experiments indicated that both FrI and FrII $(0.2 \%$ w/v) interacted with concanavalin A to give zones of precipitation approximately midway between the test and lectin wells. Formation of precipitin lines could be prevented by the addition of $\alpha$-methyl glucoside or $\alpha$-methyl mannoside (each $2 \mathrm{mg} \mathrm{ml}^{-1}$ ) to the sample well, but not by sucrose. Uninoculated glucose/malt culture medium, even when concentrated fivefold, gave no reaction with concanavalin $\mathrm{A}$.

The subdivisions of both fractions obtained from gel filtration were examined for interaction with concanavalin A. Fraction Ia and FrIb both gave diffuse precipitin lines which assumed full intensity after $48 \mathrm{~h}$. In addition FrIb gave a second weak line closer to the polysaccharide well, which was coincident with lines given by FrIIa and FrIIb. Fraction IIa gave a very strong sharp band which appeared by $\mathrm{I} 6 \mathrm{~h}$ and reached full intensity by $24 \mathrm{~h}$. On the other hand, FrIIb gave a band which although sharp was of lower intensity and subsequently disappeared. The precipitin lines from polysaccharides in adjacent wells joined without spur formation. The results of experiments with other lectins were inconclusive. No interaction was observed with crude preparations of either lentil or castor oil lectins despite the fact that the former shares a common specificity with concanavalin $\mathrm{A}$ (Lis \& Sharon, r973).

\section{Staining reactions}

Solutions and dried films of FrI and FrII were strongly PAS-positive as would be expected of a markedly periodate-sensitive polysaccharide. Films dried on to glass fluoresced strongly after exposure to FITC-conjugated concanavalin A. Staining by the basic dyes Alcian Blue $8 \mathrm{GX}$ and Alcian Green $2 \mathrm{GX}$ was extremely weak or non-existent, emphasizing the absence of negatively charged groups on the polysaccharide. Solutions of the two fractions failed to stain with iodine in potassium iodide or to fluoresce or otherwise stain when treated with aniline blue, suggesting the absence of appreciable sequences of $(I \rightarrow 4)-\alpha$ and $(I \rightarrow 3)-\beta$ linkages respectively (Gorin \& Spencer, I968; Nakanishi et al., 1974).

\section{DISCUSSION}

Appreciable polysaccharide accumulation by $M$. fructigena was largely restricted to periods of rapid growth on rich media. This suggests that synthesis and secretion of the polymer(s) may be a mechanism by which sugars are set aside for later use. Such a system could be an adaptation to the organisms' natural environment, rosaceous fruits, which characteristically possess high carbon/nitrogen ratios. The rapid utilization of all readily available carbohydrate and transformation of the excess into a less accessible, albeit extracellular form, has obvious ecological advantages. Growth trial studies (S. A. Archer, unpublished observations) indicated that the polysaccharide is readily re-metabolized by M. fructigena in a similar manner to the re-utilization of extracellular glucans by Leptosphaeria albopunctata (Szaniszlo et al., 1968), Claviceps fusiformis (Banks, Mantle \& Szczyrbak, 1974), Plectania occidentalis and a Helotium sp. (Davis, Rhodes \& Shulke, 1965).

Despite the chemical complexity of the glucose/malt medium, relatively little contamination of the polysaccharide by carry-over of malt constituents was evident. Nitrogen was virtually absent from both fractions and the sugar composition was independent of the nature of the hexose supplied in the medium. This latter result is also evidence against a 
possible extracellular mode of synthesis by a glycosyl transferase type of enzyme as is known for some bacterial glucans (Robrish, Reid \& Krichevsky, I972).

The bulk of the data presented support the hypothesis that under these growth conditions $M$. fructigena secretes a single type of polysaccharide which exhibits considerable heterogeneity with respect to molecular size but possesses a considerable degree of structural uniformity. The only major chemical difference between FrI and FrII is the lower degree of branching exhibited by the latter. This, together with the difference in molecular weight, must account for the various points of physico-chemical dissemblance between the two fractions.

The intrinsic viscosities of both fractions are high, although by no means exceptional for fungal polysaccharides (Wallen, Rhodes \& Shulke, 1965; Watson et al., 1976). They are at least two orders of magnitude greater than those of the smaller proteins listed by Yang (I96I). A variety of plant polysaccharides are known to be of high viscosity (Fincher \& Stone, I974; Medcalf, D'Appolonia \& Gilles, 1968) but these are generally of considerably higher molecular weight. The polysaccharide from $M$. fructigena possesses high viscosity for a relatively small macromolecule suggesting that the molecule is asymmetric, or highly hydrated or both.

During chromatography on Sephadex G-Ioo the peak of FrI was eluted in a position corresponding to a dextran of $\bar{M}_{\mathrm{w}} 25500$. This gives a $\bar{M}_{\mathrm{w}} / \bar{M}_{\mathrm{n}}$ ratio of $\mathrm{I} \cdot 67$, a value characteristic of crudely fractionated extracellular polysaccharides showing a high degree of polydispersity (Granath \& Kvist, 1967). $K_{\mathrm{av}}$ for FrI was independent of sample concentration (within the limits of FrI solubility) indicating that sample viscosity had little effect other than increasing zone broadening (Churms, 1970). The behaviour of FrII during gel filtration is more difficult to explain. It is possible that the samples may have been contaminated with depolymerizing enzyme which was generating small oligosaccharide fragments. However, this would hardly explain the low apparent $\bar{M}_{\mathrm{w}}$ for the bulk of this fraction, suggesting some affinity between the polysaccharide and the cross-linked dextran gel. Other fungal polysaccharides also exhibit anomalous behaviour upon gel chromatography (Fleet \& Manners, 1975).

Binding of both fractions to the lectin concanavalin A is evidence that at least some of the terminal non-reducing sugar residues possess the $\alpha$-D-glucopyranosyl or $\alpha$-D-mannopyranosyl configuration (So \& Goldstein, 1967). Interaction of concanavalin A with polysaccharides also seems dependent upon the latter having a branched structure (Goldstein, Hollerman \& Merrick, 1965); the present results are in accord with such a view.

Neither the optical rotation nor the infrared spectrum provided convincing evidence for a preponderance of either $\alpha$ - or $\beta$-glucosidic linkages. It appears that both are probably present, a view supported by the results of preliminary enzymic analyses (S. A. Archer, unpublished observations).

The occurrence together of $\mathrm{I} \rightarrow 4$ linkages and a branched structure is an unusual feature for a fungal extracellular glucan. Those possessing $\mathrm{I} \rightarrow 4$ linkages generally have an essentially linear structure and an $\alpha$-configuration, for example pullulan and the glucan from Tremella mesenterica (Gorin \& Spencer, 1968; Fraser \& Jennings, 1971). The most frequent linkage type for branched fungal glucans is $(\mathrm{I} \rightarrow 3)-\beta$ with branching via $(\mathrm{I} \rightarrow 6)-\beta$. A number of essentially similar polysaccharides of this type have been described (Buck et al., 1968; Gorin \& Spencer, 1968; Marshall, 1974) of which sclerotan from the related organism $S$. sclerotiorum is one example. The presence of an appreciable proportion of I $\rightarrow 2$ linkages within the main chain is another unusual feature, although this structure has been reported for bacterial polymers (Putman et al., I950).

Although structurally the polysaccharide from $M$. fructigena most closely resembles that secreted by $M$. fructicola, there are important differences. Thus although the degree of branching is similar to that reported by Feather \& Malek (1972), the predominant linkage is different. The glucan from $M$. fructicola contained a predominance of $\mathrm{I} \rightarrow 3$ bonds, a 
linkage virtually absent in the polysaccharide from $M$. fructigena. This is surprising in view of the close phylogenetic relationship between the two organisms and suggests that one or both fungi may secrete more than a single polysaccharide, as is known for Aureobasidium pullulans (Gorin \& Spencer, 1968). However there is no evidence for this in $M$. fructigena, a chemically near-identical polysaccharide being produced in all media which supported secretion.

We thank Dr A. Couper, School of Chemistry, Bristol University, for undertaking and analysing the ultracentrifugation experiment.

\section{REFERENCES}

Archer, S. A. (1973). Pellet form of growth of Sclerotinia fructigena in shake culture. Transactions of the British Mycological Society 6o, 235-244.

Banks, G. T., Mantle, P. G. \& Szczyrbak, C. A. ( I974). Large-scale production of clavine alkaloids by Claviceps fusiformis. Journal of General Microbiology 82, 345-36I.

Barker, S. A., Bourne, E. J., STACey, M. \& WhIFFEN, D. H. (I954). Infrared spectra of carbohydrates. Part I. Some derivatives of D-glucopyranose. Journal of the Chemical Society 17 I-I 76.

Buck, K. W., Chen, A. W., Dickerson, A. G. \& Chain, E. B. (I968). Formation and structure of extracellular glucans produced by Claviceps species. Journal of General Microbiology 51, 337-352.

Churms, S. C. (I970). Gel chromatography of carbohydrates. Advances in Carbohydrate Chemistry and Biochemistry 25, 13-5I.

Clamp, J. R. (1974). Analysis of glycoproteins. Biochemical Society Symposia 40, 3-I6.

DE ClerCK, J. (1957). Textbook of Brewing, vol. I, p. 302. London: Chapman \& Hall.

Davis, E. N., Rhodes, R. A. \& Shulke, H. R. (1965). Fermentative production of exocellular glucans by fleshy fungi. Applied Microbiology r3, 267-27I.

Devor, A. W. (I950). Carbohydrate tests using sulphonated $\alpha$-naphthol. Journal of the American Chemical Society 72, 2008-2012.

Dubois, M., Gilles, K. A., Hamilton, J. K., Rebers, P. A. \& SMith, F. (1956). Colorimetric method for the determination of sugars. Analytical Chemistry 28, 350-356.

Feather, M.S. \& MALEK, A. (1972). A highly branched exocellular D-glucan from Monilinia fructicola. Biochimica et biophysica acta 264, I03-I05.

Fincher, G. B. \& Stone, B. A. (I974). A watersoluble arabinogalactan-peptide from wheat endosperm. Australian Journal of Biological Sciences 27, I I 7-I32.

Fleet, G. H. \& Manners, D. J. (I975). Gel chromatography of polysaccharides. Biochemical Society Transactions 3, 98I-983.

Fraser, C. G. \& Jennings, H. J. (197I). A glucan from Tremella mesenterica NRRL-Y6 58 . Canadian Journal of Chemistry 49, 1804-I807.

Goatley, J. L. (I968). Production of exocellular polysaccharides by Alternaria solani. Canadian Journal of Microbiology 14, 1063-1068.

Goldstein, I. J., Hollerman, C. E. \& Merrick,
J. M. (1965). Protein-carbohydrate interaction. I. The interaction of polysaccharides with concanavalin A. Biochimica et biophysica acta 97, 68-76.

Gorin, P. A. J. \& Everleigh, D. E. (1970). Extracellular 2-acetamido-2-deoxy-D-galacto-D-galactan from Aspergillus nidulans. Biochemistry 9, 50235027.

Gorin, P. A. J. \& SPencer, J. F. T. (I968). Structural chemistry of fungal polysaccharides. Advances in Carbohydrate Chemistry 23, 367-4I 7 .

Granath, K. A. \& Kvist, B. E. (1967). Molecular weight distribution analysis by gel chromatography on Sephadex. Journal of Chromatography 28, 69-8I.

Hughes, K. W. \& Clamp, J. R. (1972). Use of gas chromatography in periodate oxidation studies of glycopeptides and related materials. Biochimica et biophysica acta 264, 418-425.

Lis, H. \& Sharon, N. (1973). The biochemistry of plant lectins (phytohaemagglutinins). Annual Review of Biochemistry 42, 54I-574.

Lowry, O. H., Rosebrough, N. J., Farr, A. L. \& RANDALL, R. J. (195I). Protein measurement with the Folin phenol reagent. Journal of Biological Chemistry 193, 265-275.

Marshall, J.J. (I974). Application of enzymic methods to the structural analysis of polysaccharides. Part I. Advances in Carbohydrate Chemistry and Biochemistry 30, 257-370.

Medcalf, D. G., D’Appolonia, B. L. \& Gilles, K. A. (I968). Comparison of chemical composition and properties between hard red spring and durum wheat endosperm pentosans. Cereal Chemistry 45, 539-549.

Nakanishi, I., Kimura, K., Kusui, S. \& Yamazaki, E. (1974). Complex formation of gel-forming bacterial $(\mathrm{I} \rightarrow 3)-\beta$-D-glucans (curdlan-type polysaccharides) with dyes in aqueous solution. Carbohydrate Research 32, 47-52.

Pearse, A. G. E. (I968). Histochemistry, Theoretical and Applied, 3rd edn, vol. 1. London: Churchill.

Putman, E. W., Potter, A. L., Hodgson, R. \& \& HASSID, W. Z. (1950). The structure of crown gall polysaccharide I. Journal of the American Chemical Society 72, 5024-5026.

ReISS, J. (I97I). Cytochemical detection of a layer of mucilage around the hyphae of Cercosporella herpotrichoides. Transactions of the British Mycological Society 56, 48 I-482.

Robrish, S. A., Reid, W. \& KRICHeVsKy, M. I. (1972). Distribution of enzymes forming polysaccharide from sucrose and the composition of 
extracellular polysaccharide synthesized by Streptococcus mutans. Applied Microbiology 24, 184190.

Shat, R. H. \& Loewus, F. (1967). Synthesis of methyl D-galacturonate from D-galactose or D-galacturonic acid: preparation of methyl-1 ${ }^{14} \mathrm{C}$ D-galacturonate using methyl- ${ }^{14} \mathrm{C}$ iodide. Carbohydrate Research 4, 40I-407.

So, L. L. \& Goldstein, I. J. (1967). Protein-carbohydrate interaction. IX. Application of the quantitative hapten inhibition technique to polysaccharide-concanavalin $\mathbf{A}$ interaction. Some comments on the forces involved in concanavalin A-polysaccharide interaction. Journal of Immuno$\log y$ 99, $15^{8}-163$.

Szaniszlo, P. J., Wirsen, C. \& Mitchell, R. (I968). Production of a capsular polysaccharide by a marine filamentous fungus. Journal of Bacteriology 96, I474-I483.

TANner, M. J.A. \& Anstee, D. J. (1976). The membrane changes in $\mathrm{En}\left(\mathrm{a}^{-}\right)$human erythrocytes: absence of the major erythrocyte sialoglycoprotein. Biochemical Journal r53, 27 I-277.

Thomas, R. C. (1930). Composition of fungus hyphae. II. Sclerotinia. American Journal of Botany 17, 779-788.

Trevelyan, W. E., Procter, D. P. \& Harrison, J.S. (1950). Detection of sugars on paper chromatograms. Nature, London 166, 444.
W Allen, L. L., Rhodes, R. A. \& Shulke, H. R. (1965). Physical properties and chemical composition of $\beta$-glucans from fleshy fungi. Applied Microbiology $13,272-278$.

Watson, P. R., SAndford, P. A., Burton, K. A., Cadmus, M. C. \& Jeanes, A. (1976). An extracellular fungal polysaccharide composed of 2-acetamido-2-deoxy-D-glucuronic acid residues. Carbohydrate Research 46, 259-265.

Whistler, R. L., Bushway, A. A. \& Singh, P. P. (1976). Non-cytotoxic, antitumour polysaccharides. Advances in Carbohydrate Chemistry and Biochemistry 32, 235-275.

Willetts, H. J. (197I). The survival of fungal sclerotia under adverse environmental conditions. Biological Reviews 46, 387-407.

Willetts, H.J. (1972). The morphogenesis and possible evolutionary origins of fungal sclerotia. Biological Reviews 47, 515-536.

YANG, J. T. (196I). The viscosity of macromolecules in relation to molecular conformation. Advances in Protein Chemistry 16, 323-400.

ZAJIC, J. E. \& LeDUY, A. (1973). Flocculant and chemical properties of a polysaccharide from Pullularia pullulans. Applied Microbiology 25, 628-635. 